\title{
Urban water bodies as the basis for functioning of public spaces
}

\author{
Valentina Kurochkina ${ }^{1, *}$ \\ ${ }^{1}$ Moscow State University of Civil Engineering, 26, sh. Yaroslavskoe, 129337, Moscow, Russia
}

\begin{abstract}
Recently, housing construction in cities has been carried out at a high rate. Increasingly, urban abandoned and flooded depressive spaces near water bodies (often rivers), which were previously used as industrial facilities or temporarily used, are becoming the sphere of architectural and landscape transformations. The restoration of such territories helps to improve the quality of urban space and improve its ecological properties. Correct development of territories near rivers and various water bodies has a great health-improving effect on the urban environment, improves its natural and climatic conditions. In addition, social and economic factors play an important role in this process, since such transformed territories and territories adjacent to them significantly increase investment attractiveness. This paper examines modern approaches to the development of urban public spaces, based on the formation of architectural environments that ensure the relationship of urban development with water bodies and adjacent territories. The paper notes that water bodies are not only an important component of the natural-ecological framework, but are also the basis for the framework of urban-planning natural-technogenic systems as a whole. And the creation of a continuous urban fabric is impossible without the organization of a 'water' line of development, provision of compositional, functional and communication interconnection of open urban and water spaces, which is actively being introduced today in architectural and urban planning practice. The paper examines the role of water bodies in the ecological system of the city, as well as in its structure as a whole. The aim of the study is to identify the features of the formation of a public urban space, to determine the patterns of its development, to identify criteria that reflect the nature, scale and features of the impact of urbanization on a water body. Some principles of revitalization of coastal areas, as well as the creation of a system of publicly accessible, compositionally expressive spaces are considered. The principles of space transformation aimed at the formation of a holistic image of the city, as well as the impact of such a spatial arrangement of urban and water bodies on the safety and quality of the urban environment are considered.
\end{abstract}

\footnotetext{
*Corresponding author: kurochkina@mgsu.ru
} 


\section{Introduction}

In recent decades, housing construction has been progressing rapidly around the world. According to some experts, the urban population will be $70 \%$ by 2050 . The problem of organizing urban space especially affects Russia, where already now this figure reaches almost $75 \%$.

Most large cities were built on the banks of rivers, which, being a natural symbol of the city, to a greater or lesser extent influenced the formation of public urban space. Since ancient times, rivers have been the main means of communication. The use of water gradually expanded and, therefore, the importance of water resources for the city increased. The transformation of the hydrological networks of urban areas was determined by the history of the formation of the city, the peculiarities of building at different stages of the formation of the urban environment [1].

For a long period of time, the coastal areas and adjacent territories were considered as unsuitable for building. This was caused by such factors as seasonal flooding, inaccessibility, and often such territories were the peripheral zones of the city. With the growth of cities, social and economic conditions changed, as well as the needs of people. The formation of a modern urban environment required new approaches to the reclamation of free urban areas and the development of already built up urban areas on the basis of principles of their integrated development and unity, taking into account the features of building a comfortable and safe urban environment. At the beginning of the 21 st century, a large-scale rethinking of the requirements for the functional saturation of these spaces took place, and their role as an often unused territorial urban reserve was replaced by their intensive development as an urban space [2].

Abandoned and flooded depressive spaces near water bodies (often rivers), which were previously industrial (factories, plants), transport (port facilities, shipyards), agricultural (farms and complexes) objects or temporarily used objects (mainly for warehouses, landfills, parking lots)are increasingly becomingthe objects of architectural and landscape transformations of urban areas.

The term 'depressive' in relation to territories and spaces was originally socio-economic in nature. The term 'depressive' was applied to urban areas at the beginning of the last century in Great Britain in connection with the crisis of 1929. At that time, the old industrial centers, the main industry of which was the coal industry, were classified as depressive [3]. The characteristic features of such areas were identified: 1. the lack of opportunities for the functioning of various types of spheres of activity, industries and 2. the lack of conditions for an independent resolution of the current crisis situation. Depending on the level of these depressed spaces, one can distinguish: 'depressed regions' (individual cities or territories), 'depressed districts' (parts of cities) or 'depressed objects' (local buildings).

The depressed regions are fundamentally different from the backward ones, since, with modern socioeconomic indicators lower than the national average, in the past, these regions were developed, and in some industries, they occupied leading positions in the country [3]. Therefore, depressed territories have sufficient economic potential, but as a result of the structural crisis characterized by a steady decline in production and real incomes of the population, growing unemployment, they do not have the conditions for an independent resolution of the current crisis situation. Unclaimed abandoned buildings appear on such territories, which, at the same time, may have historical value. Since there is a long-term decline in environmental quality indicators in such spaces, the term 'depressive' is increasingly used in relation to spaces in urban planning and ecology. The signs of 'depression' include: the presence on the territory of abandoned, destroyed or dilapidated structures for various purposes, with varying degrees of moral and physical deterioration. 
Such depressive spaces include dilapidated low-rise housing stock, disturbed or empty areas, etc. Oftendepressivespacesappearnearwaterbodies.

Today, the need to revitalize (from Lat. Re-vita - return to life) such territories and coastal areas in order to create a system of publicly accessible, compositionally expressive spaces, the need for their systematic architectural and landscape organization has become absolutely obvious. The main principle of revitalization is to reveal new possibilities of old forms, taking into account their modern functions. In the process of revitalization, an integrated approach is used with the aim of preserving the uniqueness, authenticity, identity and historical resources of the urban environment.

According to [4], depending on funding, two types of revitalization are distinguished: "top-down" and "bottom-up". Projects of the first type, as a rule, are characterized by the fact that they are initiated by the authorities, which often provide financial support (publicprivate partnership projects). As a rule, they are very expensive and are characterized by large volumes of construction. Projects of the second type (bottom-up) are mostly based on private initiative, i.e. restoration (reconstruction) of decaying urban areas by means of improvement, which occurs as a result of attracting the attention of wealthy residents to these areas (i.e. mainly at the expense of private funds). Such projects are carried out mainly on the "bottom-up" initiative. This phenomenon is now called gentrification (a special case of revitalization) [5].

The basic principles of revitalization in the formation of new water and near-water spaces can be formulated as follows:

- de-industrialization of coastal areas;

- $\quad$ return of maximum accessibility to water bodies;

- creation of new or restoration of old public centers, which could be places of attraction - the centers of a quarter or district;

- stage-by-stage transformation of water bodies and adjacent territories into recreation areas, walking alleys, squares, parks and embankments (revitalization) in order to ensure convenient pedestrian accessibility of zones;

- transition to manageable integrated natural and man-made systems based on the principles of sustainable development of territories.

Revitalization is designed to provide people with a high-quality, favorable and safe environment for living. Therefore, it is closely related to the renovation of territories, which serves to improve (or form) the process of developing a harmonious connection between the city and the environment. The following models of territory transformation can be distinguished (Fig. 1).

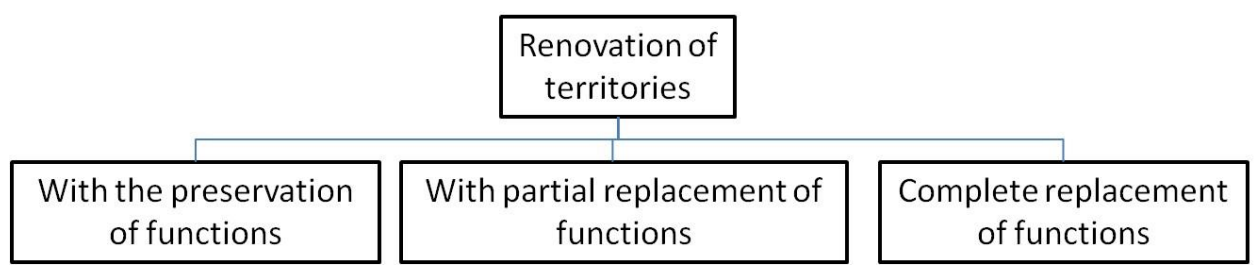

Fig. 1. Territory transformation models.

Such an integrated approach can contribute to the formation of an aesthetically complete environment, in which the water urban space is considered as an important element in the general planning of the city, in the construction of architecturally significant public facilities, as a place of social activity in the city and places of intensive recreation $[6,7]$. The implementation of the re-vitalization is possible in the following areas: 1. restoration of the socio-economic potential of the territories; 2. restoration or construction of new 
complexes of structures; 3 . creation of a logistics infrastructure; 4. restoration of water and adjacent spaces to favorable sanitary and hygienic and environmental indicators.

Nowadays, the construction of large residential, business, public and recreational complexes on the coastal areas and adjacent territories with the inclusion of a water body as a central component of the overall composition has already begun actively. Such territories have undeniable architectural and landscape merits, which make it possible to implement unique projects with their own artistic characteristics. These projects include the Red October factory complex in Moscow, the Albert Dock in Liverpool (Great Britain), the Quai Branly Museum in Paris (France), the Hafencity district in Hamburg (Germany) (Fig. 2).

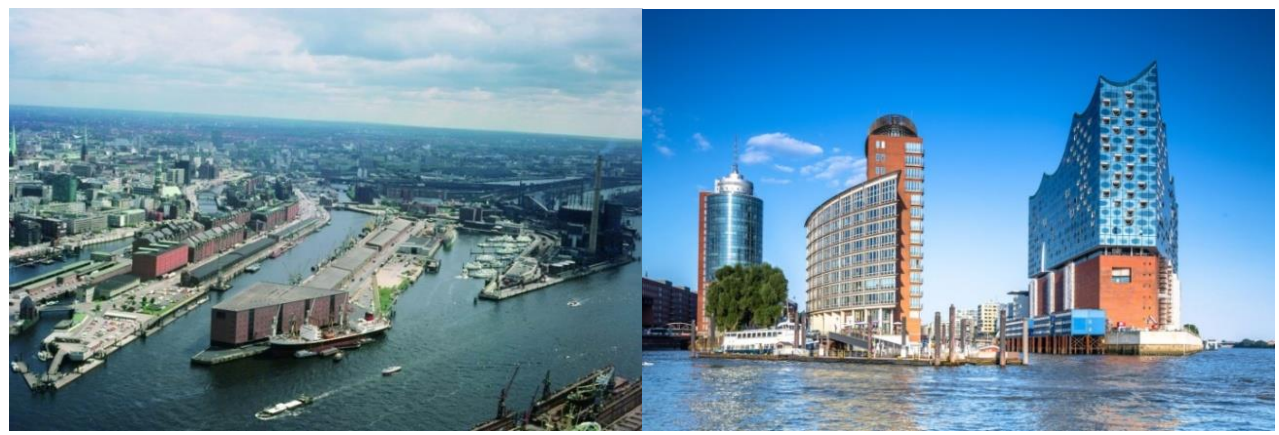

Fig. 2. HafenCity Hamburg (Hamburg, Germany). Left: early 90s, right - 2013.

This project is considered the largest urban renovation project in Europe in terms of area. Apart from the water surface, architectural and landscape transformations have affected an area of about 220 hectares. With the formation of the European Union, the turnover of the port of Hamburg has noticeably decreased. The subsequent strengthening of border security measures led to a further decrease in freight traffic. Despite the fact that Hamburg remains the second most important container port in Europe after Rotterdam, the city authorities decided to revitalize this territory. The project was launched in June 2001. The new district of the city, according to the project, should include 10 new isolated quarters, increasing the central part of the city by $40 \%$.

New hotels, shops, office and residential buildings appeared on the restored territory (Fig. 3). The construction of buildings was carried out using new construction technologies aimed at maximizing the preservation of the environment.

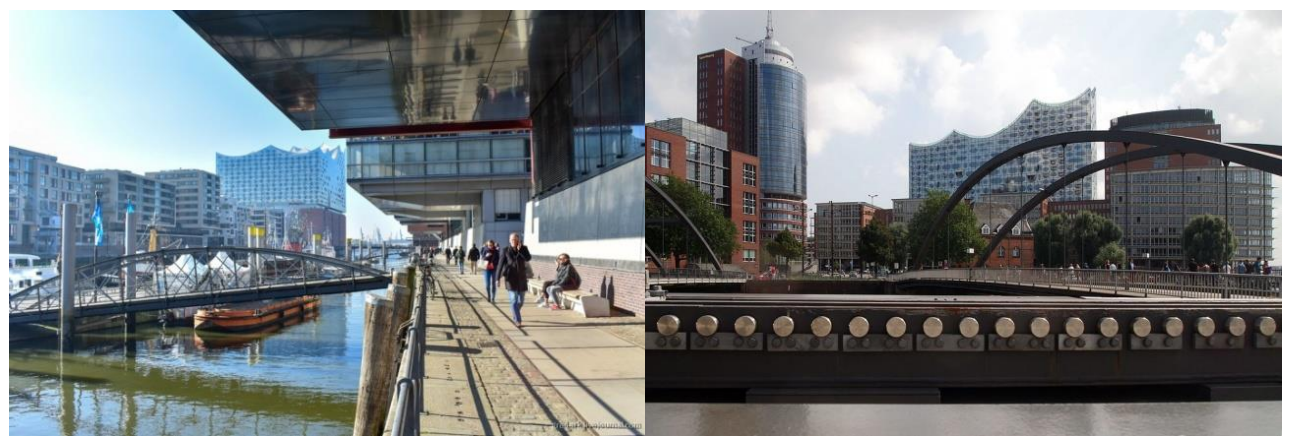

Fig. 3. Hanseatic Trade Center (HafenCity,Hamburg).

The docks in Liverpool are another prime example. Today, Albert Dock is the most famous landmark of Liverpool (Fig. 4). In 2008, it was declared the cultural capital of 
Europe, and it was also included in the five most popular cities for buying real estate in the UK.

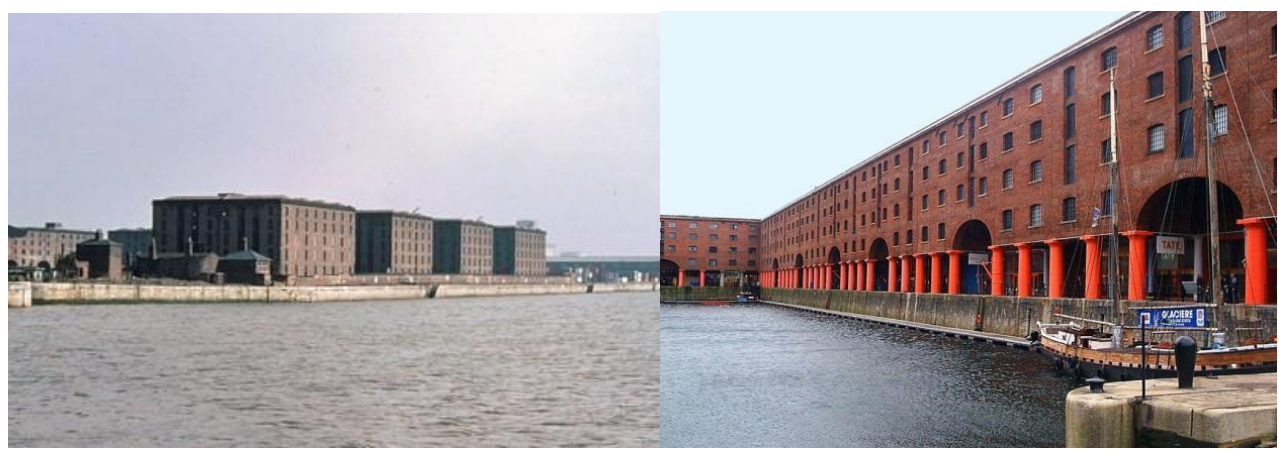

Fig. 4. Albert Dock in Liverpool (UK): left - 1979, right - today.

It is obvious that the involvement in the turnover of territories from among inefficiently used areas, mainly depressed spaces, will provide a qualitative increase in the attractiveness of the city. The application of the principles of such an integrated development of urban areas in Russia can become a tool for improving safety, comfort and quality of the environment. This, in turn, will ensure the integrity and sustainable development of territories, which will ensure the transition of Russian cities to modern development models.

\section{Materials and methods}

Urban spaces, their landscape and urban planning development, as well as interaction with water bodies on which they develop, largely depend on the conditions for the formation of urban planning natural and man-made systems: natural and landscape, environmental, engineering and construction, transport, socio-economic, socio-cultural, administrative, geopolitical ones.

All these components form a unique natural and man-made system, as well as forms of interaction with the water environment that are unique for each city. As mentioned above, the basic principles of the formation of the urban environment today should be based on the concept of sustainable development of the city and adjacent territories, as well as the principles of compliance of the used urban area with modern requirements.

To describe the processes of the urban planning system, the concepts of 'frame' and 'urban fabric' (or 'filling') are used. From the point of view of the intensity of use, the frame and the fabric are the basic structural elements [8]. The framework of the city, as a relatively unchanged, stable in time basis of the spatial and planning organization of the urban planning system, in fact, is a backbone, transport and communication corridors, the zone of influence of which is the most developed and populated. The town-planning framework fixes the geometry of the urban plan and predetermines the tendencies of the territorial development of the city. Urban fabric is the territory of the city occupied by residential, public and industrial buildings. Urban fabric is less stable throughout its spatial organization. If we distinguish the central, middle and peripheral zones in the city, then, unlike the central ones, the peripheral zones will be filled less intensively and more uniformly [9]. At the same time, intensive interaction between the city center and its outskirts will increase the level of economic attractiveness of peripheral areas and should become a kind of basis for the development of the entire city as a whole [10]. 
Urban planning natural-man-made systems are extremely complex and are characterized by a large number of qualitative and quantitative parameters. Such parameters should reflect biological, economic, social, technological and other processesoccurring in the urban environment. An important role in the formation of a comfortable and high-quality urban environment is played by indicators that reflect the ecological state of the space. To create an objective criterion apparatus for choosing such parameters, it is necessary to structure the urban space according to a certain concept. According to the author, such a concept should include the following principles.

1. Water bodies (including town-forming rivers) are not only a natural and ecological framework, but are also the basis for the framework of urban planning natural-man-made systems in general. It is due to them that the formation of the framework of the city occurs to a large extent and the integrity of the urban planning systems of cities as a whole is ensured.

2. In order to ensure the integrity of the urban fabric, improve the quality of the environment, one of the priority areas of modern research should be the study of depressive spaces of cities.

If we talk about the formation of the urban framework, then, according to the author of the paper, water bodies (such as rivers, lakes, sea shores, etc.) are not only one of the main city-forming elements of the ecological framework, to which the planning and functional systems of these cities have somehow adapted in space and time, but also occupy a key place in the structure of the city as a whole. Water bodies are also transport routes.

Therefore, we will assume that it is water bodies that largely form the framework of the city (Fig. 5) and ensure the integrity of the urban planning natural-man-made system as a whole (including the water and natural systems of the city).

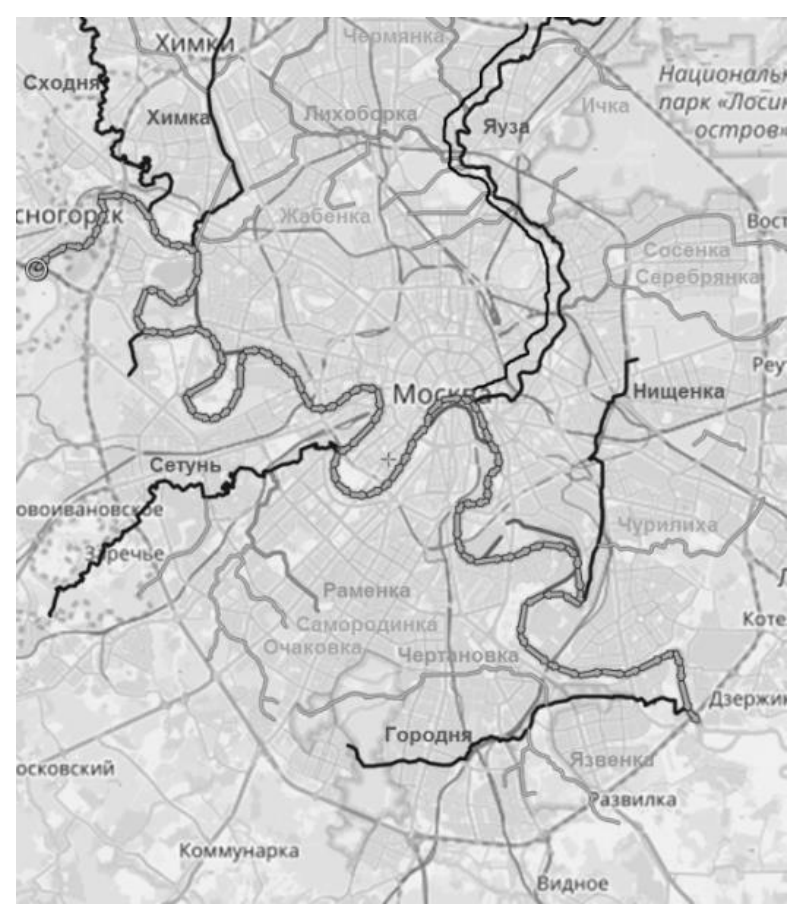

Fig. 5. Fragment of the hydrographic network of Moscow.

City embankments of rivers and water areas are complex hydrotechnical(engineering) and architectural structures. Along with the surrounding residential and public buildings of the city, the structure of river embankments and water areas may include (Fig. 6): 
- $\quad$ community centers;

- hydrotechnical structures;

- $\quad$ structures for strengthening slopes and terraces;

- $\quad$ elements of landscaping and greening;

- $\quad$ other engineering structures;

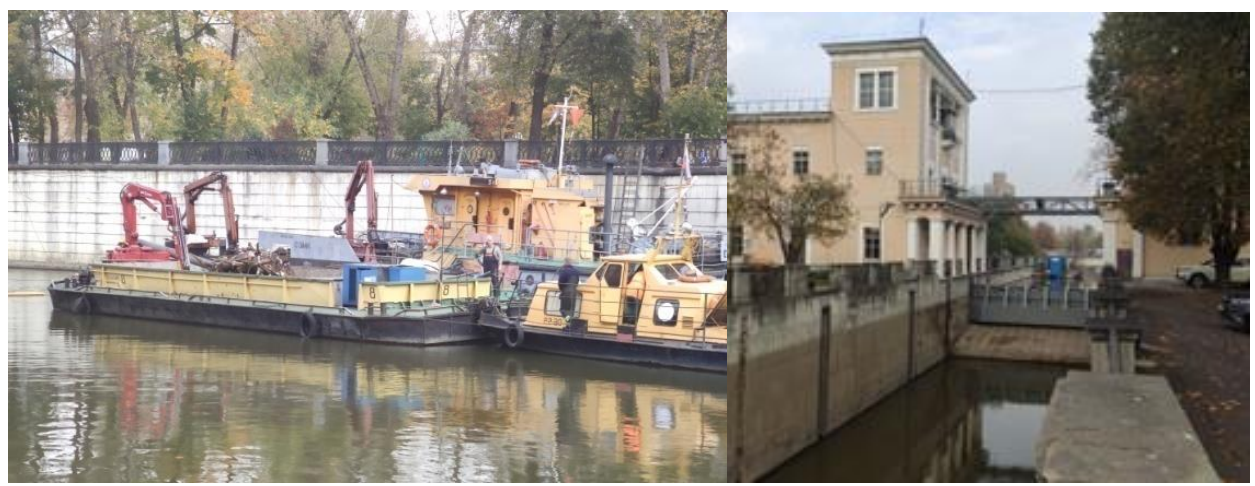

Fig. 6. Yauza river embankment.

Since it is objectively impossible to ensure the conditions for the existence of a water body on the territory of a city as in undisturbed nature, the term 'nature-friendly state' has appeared in the special literature in relation to urban water bodies, which is used in the development of projects for the recreation, reconstruction, repair and operation of urban water bodies. They live a peculiar life and require special conditions for survival. Urban water bodies must be exploited, i.e. in contrast to natural conditions, when the existence of a water body is provided by nature itself, in conditions when the existence of an urban water body must be ensured by a person, since the water body itself is not able to cope with technical transformations and the amount of pollution that come from the urban area [11].

Therefore, another important area in the formation of sustainable urban planning natural and man-made systems and the implementation of the integrated development of urban areas is to ensure the environmental safety of water bodies. The importance of this problem is caused by the fact that rivers (especially small ones), lakes and ponds in urban areas are very special natural formations that are subject to intense anthropogenic impact [12].

The ecological safety of water bodies is understood as a complex of factors that ensure the stable state of the reservoir and the adjacent territory within the standard indicators of water quality, the level of pollution of the soil bed and the coastal zone, ensuring the guaranteed absence of threats to the health of the population and the existence of the water body in accordance with the purpose of the reservoir and the nature of water use: for recreation, water supply, fish farming and water disposal [13].

Improving the safety and quality of the urban environment is impossible without the restoration of depressed urban spaces. Although the 'depressive' areas include territories that in the past had a sufficiently high level of production and technical potential and qualifications of personnel, which lost these economic advantages and cannot overcome the current crisis at the expense of internal resources [14].However, in conditions of urban development, we often come across unfinished buildings, which also have the properties of 'depression'. Although such structures, both from a legal point of view and from the point of terminology, do not strictly fit this definition, nevertheless, they are inherently depressed spaces for which a long-term decline in environmental quality indicators is also characteristic. Therefore, we will refer them to 'conditionally depressive' spaces. Also, construction in progress in urban settings is often located near water bodies. 
Identification of 'depressive' and 'conditionally depressive' spaces in the urban fabric requires the determination of its qualitative parameters, such as the localization of zones of influence of depressive spaces, their parameters and properties. In the conditions of close urban development, which primarily affects the central areas of the city, 'depressive' spaces, especially of the middle and central zones, seem to be relevant areas for research. Determination and localization of the desired 'depressed' spaces will help improving the safety and quality of public urban spaces, which means it will contribute to an increase in the level of comfort and investment attractiveness of these territories.

\section{Research results}

In order to obtain information about the nature, scale and characteristics of the impact of urbanization on a water body (taking into account the fact that most cities were built on the banks of rivers, somehow affecting the formation of urbanized territories), it is necessary to take into account the following factors (and criteria/indicators based on them) [13]:

- $\quad$ features of the formation of the city (identity);

- location of the urbanization center in the immediate vicinity of the water body (watercourse) with the determination of the degree of its influence on the formation of the urbanized space;

- integrity of the urbanized space, of which water bodies are an integral part (harmonious interaction of water areas and adjacent territories);

- different scales of water bodies (streams) and centers of urbanization in terms of water content, population and nature of production;

- influence of various territorial and climatic zones;

- $\quad$ landscape features of the area;

- $\quad$ analysis of water bodies with various hydromorphological parameters, including central and small watercourses (identification of the nature of the use of water bodies, the degree of their anthropogenic change, including biota, the level of pollution).

- ability to develop and transform over time the system "urbanized territory - water body" at any stage of its existence.

The above factors that determine the formation of the urban environment and the indicators that determine these factors are presented in Table 1.

Table 1. Conditions for the formation of urban natural and man-made systems and factors of influence of urban space and water environment.

\begin{tabular}{|c|c|}
\hline $\begin{array}{l}\text { Conditions for the } \\
\text { formation }\end{array}$ & Factors \\
\hline socio-cultural & $\begin{array}{l}\text { 1. } \\
2 . \quad \text { identity (or features of the formation of the city) } \\
\text { 3. different scales of water bodies (streams) and urbanization } \\
\text { centers by water content, population and nature of production } \\
\text { 4. opportunity for the development and transformation of the } \\
\text { urban planning natural and technogenic system in time }\end{array}$ \\
\hline socio-economic & $\begin{array}{l}\text { 1. different scales of water bodies (streams) and urbanization } \\
\text { centers by water content, population and nature of production } \\
2 . \quad \text { integrity of the urbanized space } \\
3 . \quad \text { opportunity for the development and transformation of the } \\
\text { urban planning natural and technogenic system in time }\end{array}$ \\
\hline $\begin{array}{l}\text { engineering } \\
\text { construction }\end{array}$ & $\begin{array}{ll}1 . & \text { identity (or features of the formation of the city) } \\
2 . & \text { integrity of the urbanized space } \\
3 . & \text { influence of different territorial and climatic zones } \\
\text { 4. } & \text { landscape features of the area }\end{array}$ \\
\hline
\end{tabular}




\begin{tabular}{|c|c|}
\hline & $\begin{array}{l}5 . \text { different scales of water bodies (streams) and urbanization } \\
\text { centers by water content, population and nature of production } \\
6 \text { the presence of water bodies with different } \\
\text { hydromorphological parameters and varying degrees of urbanization } \\
\text { impact }\end{array}$ \\
\hline $\begin{array}{l}\text { natural } \\
\text { landscape }\end{array}$ & $\begin{array}{l}\text { 1. location of the urbanization center in the immediate vicinity } \\
\text { of the water body } \\
2 \text { influence of different territorial and climatic zones } \\
3 . \\
4 . \quad \text { landscape features of the area } \\
\text { hydromorphological parameters and varying degrees of urbanization } \\
\text { impact }\end{array}$ \\
\hline ecological & $\begin{array}{l}\text { 1. location of the urbanization center in the immediate vicinity } \\
\text { of the water body } \\
\text { 2. } \\
\text { influence of different territorial and climatic zones } \\
4 \text { landscape features of the area } \\
\text { hydromorphological parameters and varying degrees of urbanization } \\
\text { impact } \\
5 . \\
\text { centers different scales of water bodies (streams) and urbanization }\end{array}$ \\
\hline transport & $\begin{array}{l}\text { 1. location of the urbanization center in the immediate vicinity } \\
\text { of the water body } \\
2 \text { different scales of water bodies (streams) and urbanization } \\
\text { centers }\end{array}$ \\
\hline
\end{tabular}

Let's consider these factors in more detail.

The modern urban environment should have spatial, functional, social, and transportdiverse. At the same time, industry indicators should be replaced by indicators characterizing the compliance of the urban area used with modern requirements while ensuring the quality and safety of the urban environment.

These indicators include factors reflecting biological, economic, social and technological processes taking place in the urban environment.

Socio-cultural, socio-economic and engineering-construction factors include:

1. Identity (or peculiarities of the city formation) is determined by the history of the formation of the city, the peculiarities of building at different stages of the formation of the urban environment, the presence of water bodies. So, for example, most large cities were built on the banks of rivers, which, being a natural symbol of the city somehow influenced the formation of public urban space. Thus, city-forming rivers, like all other water bodies of the city, are an inseparable part of the urban environment, and their maximum involvement in the organization of urban space ensures the continuity of the urban fabric.

2. The integrity of the urbanized space, of which water bodies are an integral part, is impossible without the harmonious interaction of water areas and adjacent territories.

The availability of water resources makes it possible to create a comfortable living environment in the city, recreation areas that unite the urban space, for example, through embankments. Water bodies can create an atmosphere of unity and continuity in the urban fabric. And also to introduce different semantic elements into the public space to attract new categories of citizens to the park zones, for example, a playground to attract children, comfort to attract elderly people, a sports element, etc.

It is also important to take into account the social factor of the organization of the space, for example, such as the comfortable movement of users from one area to another, the growth of the flow of visitors to commercial infrastructure facilities, which is possible if commercial, cultural or leisure infrastructure facilities located in neighboring areas complement each other. And also by increasing pedestrian activity within and between 
neighborhoods, which can be achieved by making them permeable through the construction of alleys, boulevards, parks and embankments. The social factors include service factors, which reflect the level of comfort of the urban environment for citizens. These include the travel time to the place of work (transport accessibility, intensity of use), the comfort of pedestrian traffic, the level of landscaping, the availability, spatial distribution and accessibility of the territory of commercial, cultural and leisure infrastructure facilities (for each resident on a daily basis), the level of privacy for everyone.

3. Opportunity for the development and transformation of the urban planning natural and man-made system in time. Changes in the requirements for the urban environment lead to a change in its use, while the requirements for quality assurance, favorable living conditions (comfort) and safety of the urban environment are constantly increasing.

Therefore, the modern urban environment should have the possibility and ability to develop and transform in time the urban planning natural and man-made system "urbanized territory - water body" at any stage of its existence. When organizing urban space, the possibility of its spatial expansion, development and future transformation should be taken into account. As an example, we can use Moscow, which has significantly grown in recent years, increasing the scale and area of construction.

The natural and landscape, transport and environmental factors include:

1. When assessing the location of an urbanization center in the immediate vicinity of a water body and its impact on urban space, it would not be an exaggeration to say that any water body has a strong impact on the adjacent territory. The urbanized area is no exception. Water (ocean, sea, large river) can be a determining factor in the formation of the climate, for example, they can significantly soften the climate of the territory. In addition, large water bodies have a strong influence on the circulation of the atmosphere (passage of fronts, cyclones). Rivers of urbanized territories can contribute to the economic development of the territory, and vice versa. So, for example, their presence can contribute to such negative phenomena as: possible flooding of the territory, undermining the banks, activation of landslide, karst processes, water erosion, rising groundwater as a result of raising the water level in the river, etc.

The natural and landscape, environmental, engineering and construction factors include:

1. Influence of different territorial and climatic zones. To create a comfortable space, it is necessary to take into account the climatic features of the location of the city, which will determine certain engineering and construction solutions: building structures, the formation of public space.So, for example, to create a comfortable space, it is possible to create artificial shelters from coastal winds or the hot sun, for areas with poor illumination free spaces from excessive shadows. Climate features must also be taken into account when planting green spaces in public areas, etc.

2. Landscape features of the area. When organizing urban space, it is necessary to take into account the structure of the landscape of the area as much as possible, ensuring its harmonious relationship with urban development while ensuring the maximum accessibility of the territory for residents (this is also closely related to the integrity of the territories). One of its indicators is the provision of green spaces in public areas.

The socio-economic, transport, engineering and construction factors include:

1. Different scales of water bodies (streams) and urbanization centers in terms of water content, population and nature of production allow taking into account sectoral indicators that determine quantitative indicators of the development of various urban infrastructure facilities (length of roads, number of built square meters of housing), density, composition and size of the city population and etc.

The engineering, construction, natural and landscape, and environmental factors include: 
1. The presence of water bodies with different hydromorphological parameters and varying degrees of urbanization impact, including central and small streams. Urban planning factors radically affect the hydrosphere. There are two types of technogenic interference in the natural balance of surface waters: 1) change in the watercourse regime; 2) pollution of water basins. Therefore, the nature of the use of water bodies, the degree of their anthropogenic change, including biota, the level of pollution - all these factors must be taken into account in order to create a safe and comfortable environment.

Historically, the water resources of cities, in the absence of a developed sewerage and water supply systems, served as sources of water for most of the common population. Nowadays, they can be divided into two categories:

- $\quad$ water resources, which are enclosed in collectors, water supply and sewerage, i.e. those vital systems of functioning of a modern big city, without which it cannot exist.

- $\quad$ open or partially open water sources that are present in the city and make up its ecosystem: bays, rivers, lakes, canals, artificial reservoirs, fountains, cascades, etc.

Water regimes are violated on the territories of cities when natural channels of watercourses are straightened, canals and cascades of water bodies are arranged (Fig. 7). The hydrological situation is influenced by inclosing small rivers and streams into collectors, which takes place in many large cities, the construction of embankment walls with filling and urban development of coastal floodplains.

By now, the coastal territories and embankments of the Moskva River and the Yauza River have almost completely been alienated in favor of building them up with various kinds of industrial enterprises, as well as for laying routes for heavy traffic of cars and trucks. All this interferes with the life-giving ventilation of the city along the river beds, which excludes the possibility of using even the central, historical and established panoramic embankments of the capital.

Almost $1 / 3$ of the territories adjacent to the Moskva River are impenetrable, i.e. there is no way through them to approach the river by car of by foot. These are the industrial areas, public areas with limited access. The same processes especially affected the coastal areas and embankments of the Yauza River, potentially rich in relief and landscape. Almost all coastal areas and sections of the Moscow River and Yauza (as well as other small rivers in the middle and outskirts of the city) have become inaccessible to pedestrian traffic.
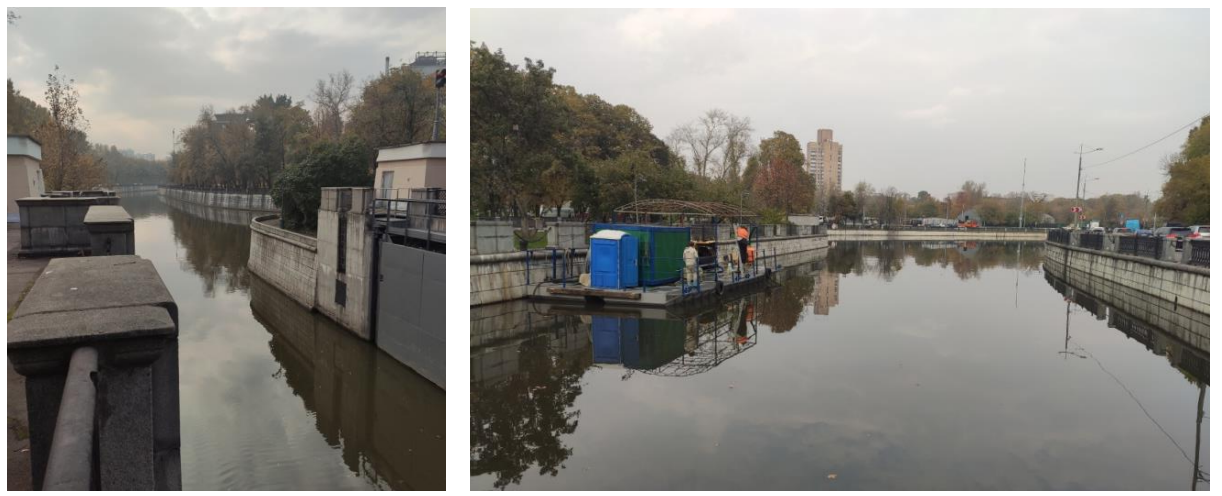

Fig. 7. Yauza river.

In addition, due to the irrational development of coastal zones and embankments of Moscow rivers, the natural ventilation of the city along their channels has significantly deteriorated, which adversely affects the overall environmental situation in the capital. The wide recreational opportunities of the territories of the embankments of Moscow rivers (Moscow, Yauza, Pekhorka, etc.) for walking, recreation, arrangement of viewpoints, green areas of boulevards, squares are almost not used, which greatly impoverishes the functional, 
socio-cultural and spatial components of the center, middle and outskirts of the city. The water in a significant part of Moscow rivers is not suitable for technical, drinking water supply and for organizing recreation and swimming due to the discharge of untreated and under-treated industrial and municipal wastewater, surface runoff, and mechanical pollution.

Pollution has a great impact on the state of water bodies. Often, major highways run along or in the immediate vicinity of river embankments, which also contribute to the level of pollution (including noise pollution).

The main pollutants include:

- pollution with oil and oil products, this phenomenon is characteristic of most urban water bodies;

- chloride pollution associated with the use of salts that simulate snowmelt;

- PAH contamination (especially benzo(a)pyrene, which is especially intensively supplied from surface runoff);

- pollution with detergents, which can cause a violation of the oxygen regime, a change in the natural course of chemical processes, poisoning of aquatic organisms and oppression of life in water bodies;

- pollution with heavy metals, the danger of pollution with which is associated with the concentration function of organisms, namely, when moving from water to aquatic vegetation, the concentration of pollutants increases as they move along trophic links.

The state of water bodies, especially river channels, largely reflects the general ecological situation in a particular region.

In an era where environmental values are prioritized, coastal areas are of particular importance in the urban environment. Gradually, water features in the city and access to water are seen as a special value that transforms the quality of life in the city, ensures safety and comfort, and gives an 'urban experience' into a sense of space. Modern urban planning standards provide for the formation of large spaces of an open landscape (parks, squares, alleys, embankments), often including water resources.

However, both parks and embankments in cities require indispensable improvement, the creation of an untouched area of nature or a natural coastline. Here I would like to give several examples of the development of water and adjacent spaces.

\section{Embankments}

The history of the formation of urban development in New York was similar to the situation that was characteristic of Moscow for a very long time. In the course of industrialization, most of the urban areas of New York were cut off from water by industrial zones, port facilities, and road infrastructure [15]. The coastline gradually began to develop from the Manhattan side, but there was no single plan. Therefore, the city authorities have developed the concept of a single water facade - "Vision 2020: NewYorkCityComprehensiveWaterfrontPlan" (Fig. 8). According to this comprehensive plan for the transformation of the water space and adjacent territories, the foundation should be laid "...to expand the possibilities of using the embankment as a single planning element in the design of parks, in construction, creation of recreation areas as a natural human habitat.This should also give impetus to the development of the economy and transport..." [16]. 


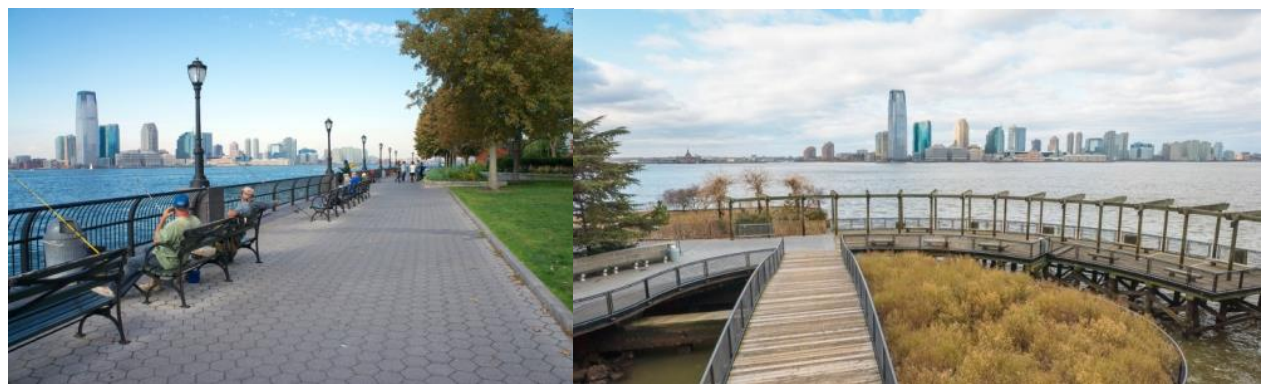

Fig. 8. Embankments of New York.

If we talk about parks, the main condition for their successful existence and popularity lies in the diversity of their surroundings, their location in the urban fabric. The park is an ensemble, on the correct arrangement of which it depends whether it will turn into an empty alienated zone or it will become a prosperous place for the citizens to spend their time.

Often water resources serve as accents in the park. The logic of the successful creation of such a territory provides for the absence of monotonous vacant places, as well as giving the park a bright, pronounced individuality. According to [17], there are four key factors for the successful functioning of the park space: complexity, centricity, as well as the solar factor and isolation. Of these four important categories, two - complexity and centricity - can be provided with water.

Complexity has two meanings - it is 'visual complexity', 'complexity of aesthetics', 'semantic complexity'. Many architects of public space use water bodies to create such a 'complex' space that 'unfolds' in time (Fig. 9).

Centricity is the most essential element of park complexity. In any park, there is a place that is the center of the park's composition. In large parks, there may be several such places. Sometimes small parks can consist of one center. In order to create or emphasize such a center, as a rule, water bodies are used, often decorated with fountains. Public spaces can often be a solution to environmental problems. An example is Queen Elizabeth Olympic Park (Fig. 9). This park was created as part of a program to transform industrial zones along the Thames.

An industrial zone used to be located on the area of Queen Elizabeth Olympic park, which previously led to severe pollution of the atmosphere, water resources and soils of the adjacent territories. Therefore, before the establishment of the park, significant work was previously carried out to clean up soil and water using modern technologies.

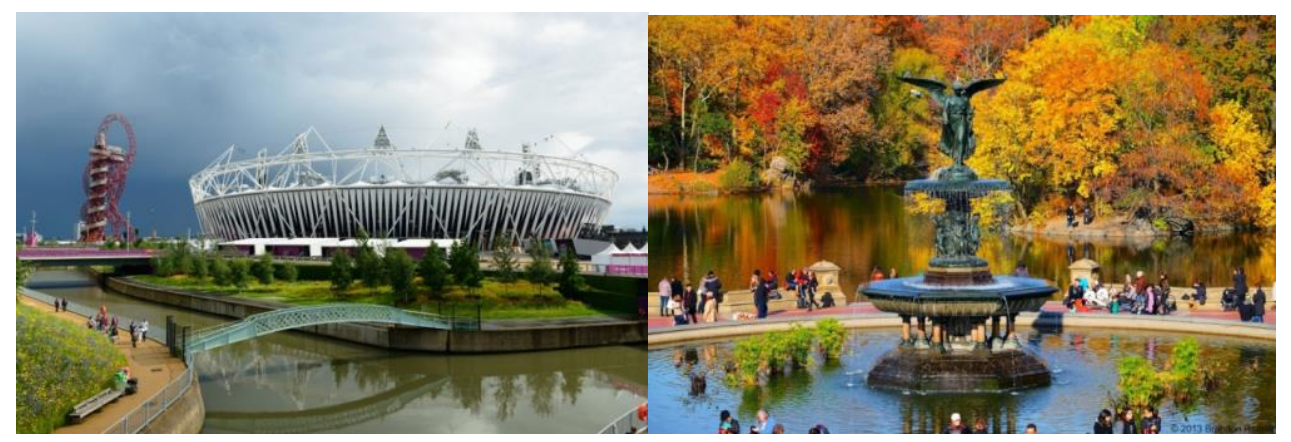

Fig. 9. Left: Queen Elizabeth Olympic park (UK), right:Park Fall Wallpaper (Central Park, New York, USA).

Correct development of territories near rivers and various water bodies has a great health-improving effect on the urban environment - it improves its natural and climatic 
conditions. The planning of embankments, promenade boulevards and parks along the banks of rivers and water bodies is also justified because clean air enters the city through the coastal areas of rivers. Correct development of the banks, their improvement and landscaping are of great social importance, since they are associated with the protection of nature and the ecology of the city.

\section{Conclusions}

The process of using the potential of rivers and other bodies of water within the city limits can be traced from the very beginning of the emergence of our city using the example of the formation of architectural ensembles for the development of coastal zones and embankments of the Moskva River, Yauza, other rivers and water areas. This process has always been directly related to the development of accessible and cheap trade waterways, the problems of construction near water. Today, the approach to urban planning has begun to change. The formation of a general concept for the development of the city in Moscow, an integral system of interconnected territories adjacent to water bodies, the transformation of rivers from a 'barrier' into a 'connecting link' in the structure of the city were called the basic principles for transformations. The result of the implementation of urban planning transformation should be an improvement in the quality of the urban environment, the efficiency of using the urban planning potential of the territories adjacent to the river.

The creation of a single interconnected system "city - water body" provides for the development and implementation of measures aimed at restoring existing and creating new water bodies, which will ensure comfortable, high-quality and safe arrangement of the urban environment, as well as sustainable development of territories [18].

1. carrying out a comprehensive reconstruction of civil and renovation of industrial buildings in the areas adjacent to river beds and water areas, implement a systematic approach to the formation and development of a modern urban environment;

2. renovation and modernization of the engineering infrastructure not only of houses to be renovated, but also of urban areas;

3. carrying out measures to improve the living environment, restore water and adjacent spaces to favorable sanitary and hygienic and environmental indicators, protect surface, groundwater, soil and atmosphere from pollution;

4. arrangement of intensive landscape gardening and landscaping on embankments and areas adjacent to river banks and water bodies;

5. cessation or significant reduction of intensive through traffic of motor transport along river embankments;

6. arrangement of public centers and recreation areas on separate sections of river embankments and water bodies and adjacent areas of parks and squares, as well as their widespread expansion and unification;

7. development of new forms of participation of residents in the solution of largescale urban projects, the development of information technologies for the management of residential buildings, the use of BIM technologies, standards for green construction, wastefree technologies in the housing and communal services system.

\section{References}

1. V.I. Telichenko, V.A. Kurochkina, Vestnik MGSU 6, 81-90 (2016)

2. E.V. Guskova, Innovations in landscape architecture. Materials of the VI scientific and practical conference, 19-23 (2010)

3. M.N. Tolchinskaya, Regional problems of economic transformation 4(17) (2008) 
4. D. Campo, B.D. Ryan, Journal of Urban Design 13(3), 291-315 (2008)

5. L. Lees, T. Slater, E. Wyly, Gentrification (New York, 2008) DOI: https://doi.org/10.4324/9780203940877

6. M. Krautzberger, Städtebauliche Erneuerung - zum Beginn einer neuen Politik für die Städte 1990 (Stadterneuerung und Städtebaulicher Denkmalschutz in den neuen Bundesländern, Berlin, 2007)

7. T. Topfstedt, Baukultur zwischen Bestandssicherung und Stadterneuerung (Jahrbuch für Architektur, Braunschweig 1991)

8. A.A. Pravotorova, Types of spatial environment in a large city (Novosibirsk, 2013)

9. K.U. Abbruch, Rekonstruktion - Ersatzneubau. Die Umgestaltung der Greifswalder Altstadt in den 1970/80er Jahren (Kontinuitäten, Berlin, 2007)

10. V.I. Telichenko, Vestnik MGSU 14(9), 1095-1095 (2019)

11. V.I. Telichenko, V.A. Kurochkina, B.L. Kirov, Urbanized territories 3, 32-39 (2016)

12. V.A. Kurochkina, T.G. Bogomolova, B.L. Kirov, Vestnik MGSU 8, 100-109 (2016)

13. T.G. Bogomolova, V.A. Kurochkina, Vestnik MGSU 4(2), 399-405 (2010)

14. A.G. Granberg, Fundamentals of regional economics (HSE, 2003)

15. E. Homberger, New York - the history of the city (Eksmo, Midgard, SPb, 2008) ISBN: 978-5-699-25413-2

16. Vision 2020: New York City Comprehensive Waterfront Plan https://www1.nyc.gov/site/planning/plans/vision-2020-cwp/vision-2020-cwp.page

17. J. Jacobs, The Death and Life of Great American Cities (Random House, New York, 1961) ISBN0-679-74195-X

18. V.I. Telichenko, Vestnik MGSU 1(15) (2020) 